\title{
Voluntary HIV Counseling and Testing Service Utilization among Pregnant Mothers in North West Ethiopia In 2014
}

\section{Bruke Gidey1, Habtamu Mellie Bizuayehu ${ }^{2 *}$ and Muluken Teshome ${ }^{2}$}

${ }^{1}$ Debay Tilat Gin Woreda health office, department of TB/HIV, East Gojjam zone, Ethiopia

${ }^{2}$ Debre Markos University, college of medicine and health science, Department of Public Health, Debre Markos, Ethiopia

\begin{abstract}
Introduction: According to 2011 Ethiopian demographic health survey result, about $2.2 \%$ mothers were HIV (Human Immunodeficiency Virus) positive in Amhara regional state. HIV testing during pregnancy is the gateway for PMTCT (Prevention of Mother to Child Transmission) of HIV though its coverage was $72.0 \%$ to $82.5 \%$ in North-West Ethiopia.
\end{abstract}

Objective: To assess VHCT (Voluntary HIV Counseling and Testing) service utilization and its determinants among pregnant mothers in North-West Ethiopia in 2014.

Methods: A community based cross sectional study using both quantitative and qualitative research methods was conducted in Enemay woreda/district. Data was collected on systematically selected 386 pregnant mothers and 4 FGDs (Focus Group Discussion) on purposively selected pregnant mothers and their partners. A pre tested closed ended structured questionnaire and open ended questions were used to collect the quantitative and qualitative data respectively. Binary logistic regression was used for multivariate analysis of quantitative data.

Result: Majority (81.6\%) of participants were known transmission of HIV during pregnancy and about three quarter (76.2\%) of them were tested for HIV in current pregnancy. In FGD, all participants were not agreed as HIV testing was important during pregnancy. The repeatedly cited reason for not up taking HIV testing during pregnancy was fear of stigma and discrimination if test result becomes positive. Pregnant mothers not knowledgeable about MTCT (Mother to Child Transmission) of HIV; have not intension for ARV Prophylaxisis, unable to bring their partner for test and mothers who believe VHCT was importance before marriage only were less likely utilizing VHCT service thus organizations working on VHCT should further enhance awareness creation by giving especial attention for these groups of pregnant mothers.

Keywords: HIV/AIDS; Voluntary HIV counseling and testing; Mother to child transmission of HIV; North-West Ethiopia; Ethiopia

\section{Introduction}

The Human Immunodeficiency Virus (HIV) continues to be a serious global public health challenges since its appearance. Globally mothers constitutes more than half $(52 \%)$ of the disease burden $[1,2]$.

Sub-Saharan Africa is one of the regions mostly affected by HIV. In 2010 , about $68 \%$ of all people living with HIV in the world were resided in the region though only $12 \%$ of the global population lives in it [3].

In Ethiopia, about 1.9\% mothers in age group of 15-49 years were HIV sero-positive. In the country about one every hundred $(0.8 \%)$ pregnant mothers were HIV sero-positive and this is an opportunity for transmition of the infection to their child $[4,5]$. Mother to child vertical HIV transmission accounts for more than $90 \%$ of pediatric AIDS (Acquired Immunodeficiency Syndrome) [6]. In 2011, the Joint United Nations Program on HIV/AIDS estimated as about 330,000 new HIV infections occurred through vertical transmission [7].

VHCT is the first step for commencing PMTCT of HIV. Without PMTCT, HIV infection would occur in 4 out of 10 deliveries among HIV-positive mothers [8]. Despite its benefits, VHCT service utilization among pregnant mothers in Northwestern Ethiopia at east Gojjam zone and Gondar town was about $72.0 \%$ [9] and $82.5 \%$ respectively [10]. In Debre Markos town about half $(55.5 \%)$ of pregnant mothers attending ANC (antenatal care) were not ready to use VHCT service [11]. In Addis Ababa which is a capital city of Ethiopia, only $18 \%$ of pregnant mothers attended the facility were coming for VHCT though $90 \%$ knew that a mother with HIV can pass the virus to her child [12].
The risk of MTCT can be reduced significantly if a woman is supplied with antiretroviral drugs [13]. To supply drugs, the mother must be aware of her HIV-positive status. Hence VHCT during pregnancy is an entry point for PMTCT service utilization. The current study was aimed to assess VHCT service utilization and its determinants among pregnant mothers.

\section{Methods and Materials}

\section{Study setting and design}

The study was conducted in Enemay woreda/district which is found in East Gojjam zone of Amhara regional state. It is located $265 \mathrm{~km}$ from Addis Ababa city, $230 \mathrm{~km}$ from Bahir Dar town and $90 \mathrm{~km}$ from Debre Markos town. The woreda comprises 34 kebeles in which five of them are urban and the rest are rural kebeles. The total population of the woreda is 187,946 out of this 41,348 are mothers of reproductive age group. There are 7 health centers all of them provide VHCT service.

*Corresponding author: Bizuayehu HM, Debre Markos University, college of medicine and health science, Department of Public Health, Debre Markos, Ethiopia, Tel: 251912356496; E-mail: habtamumellie@yahoo.com

Received November 26, 2014; Accepted February 28, 2015; Published March 09, 2015

Citation: Gidey B, Bizuayehu HM, Teshome M (2015) Voluntary HIV Counseling and Testing Service Utilization among Pregnant Mothers in North West Ethiopia In 2014. J AIDS Clin Res 6: 437. doi:10.4172/2155-6113.1000437

Copyright: $\odot 2015$ Gidey B, et al. This is an open-access article distributed under the terms of the Creative Commons Attribution License, which permits unrestricted use, distribution, and reproduction in any medium, provided the original author and source are credited. 
Community based cross-sectional study design with both quantitative and qualitative research methods were carried out from April 9-29, 2014 .

\section{Source populations}

For quantitative data, all pregnant mothers who were permanently (6 months or more) lived in Enemay woreda during the study period were the source populations.

For qualitative data, all pregnant mothers and their partners who were permanently ( 6 months or more) lived in the woreda during the study period were the source populations. All pregnant mothers and their partners who were seriously ill with coma during data collection period and HIV sero-positive pregnant mothers in which their serostatus were confirmed prior to current pregnancy were excluded in the study. HIV sero-positive pregnant mothers whose sero-status confirmed prior to current pregnancy were excluded due to knowing their status thus they would not go to health facility for VHCT.

\section{Sample size determination}

For quantitative study, sample size was determined by using single population proportion formula, using assumption of $95 \%$ confidence interval ( $\alpha=5 \%), 4.7 \%$ margin of error $(d)$ and using the proportion $(P)$ of pregnant mothers who were conducting HIV test while they were pregnant from previous study in Northwest Ethiopia (72\% ) [9].

$$
\mathrm{n}=\mathrm{Za} / 2^{2}[\mathrm{p}(1-\mathrm{p})] / \mathrm{d}^{2}
$$
386.

After adding non-response rate of $10 \%$ the final sample size was

For qualitative study, a total of four FGD sessions were conducted based on saturation of the information. Among pregnant mothers and male partners two FGDs in each group were conducted. One FGD were having nine members thus the sample size for qualitative study was 36 .

\section{Sampling procedure}

For quantitative study, all kebeles found in the woreda were included in the study and stratified as urban and rural based on residence. Stratified sampling technique was used to enhance the number of urban participants since compared to rural they are minimal in number. Then study participants were selected from each stratum proportionally. The sampling frame was prepared from list of pregnant mothers who are registered by the Enemay woreda health office. Study participants from each stratum were selected by applying systematic random sampling method. For qualitative study, focus group discussion participants were selected purposively in collaboration with kebele leaders based on giving more data about the community among candidates of couples for study. Pregnant mothers who were not included in quantitative study and partners of pregnant mothers were participants of the discussion. Study participants were selected from the prepared list of pregnant mothers that was available in woreda health office.

In order to get the home of pregnant mothers or their partners we were using the registered address which includes their full name, kebele name, village/gote name, house number, phone number (if they were having). We were inviting study participants by using phone number (for those having it) and for those not having phone we were go to at their home and invite orally to come for discussion at appointed time (Figure 1).

\section{Data collection procedure}

Quantitative data was collected by using structured closed ended

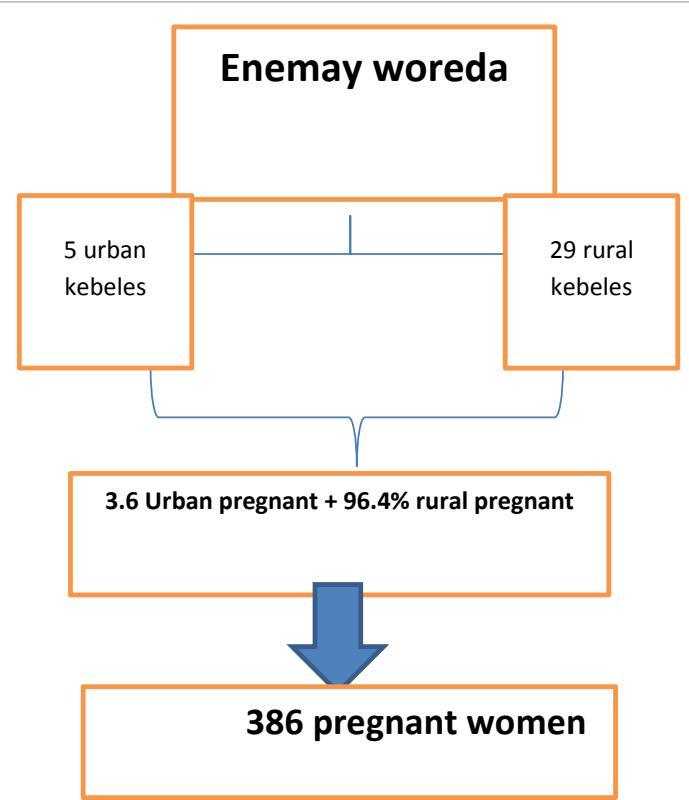

Figure 1: Schematic presentation of the sampling procedure in Enemay woreda in 2014

questionnaire which was developed by reviewing different literatures. The questionnaire was translated to Amharic as the study subject speaks Amharic and re-translated back to English to check its consistency. Before conducting the main study, pretest was carried out by trained data collectors and supervisors in two kebeles of Debay Tilat Gin woreda among 20 pregnant mothers $(5.2 \%)$ of sample and corrections were made accordingly.

Ten clinical nurses and three bachelor degree health professionals were recruited as data collectors and supervisors respectively. Training was given on purpose of the study, content of the questionnaire, and approaches to the interviewees by the principal investigators.

For qualitative data, focus group discussion was used as a data collection technique using open ended questions. Principal investigators of the study were moderator of the discussion. Each focus group discussion was taken 60-90 minutes and takes place in nearby governmental institution. The discussion was continued until saturation of the information. Discussion of the participants was recorded by tape and note was also taken by research assistants.

\section{Operational definitions}

- Positive attitude: The mothers who score more than the mean value for attitude questions

- Sufficient knowledge about HIV/AIDS and PMTCT: When respondent score more than the mean value for HIV/AIDS and PMTCT knowledge questions.

- VHCT service utilization: A woman that were tested for HIV during current pregnancy.

\section{Data analysis}

For the qualitative data, each questionnaire was given a code before data entry. Data was entered by Epi info version 3.5.1 statistical package and exported in to SPSS version 20 for analysis. Before analysis data cleaning was done using frequency, listing and sorting to identify missed values and outliers. Descriptive finding was presented using percentage, 
mean, median, and tables. And the analytic finding was presented using odds ratio. Binomial logistic regression was used to analyze the association of dependent variable with independent variables. Variables showed significant association with $\mathrm{p}$-value $<0.05$ at bivariate analysis and not collinear were entered in to multivariate analysis.

The qualitative data i.e. all hand written notes and tape recorded data were transcribed on paper in Amharic language and compiled in to thematic areas. Finally the Amharic version was translated in to English language.

\section{Ethical consideration}

Ethical clearance was obtained from the research and publications committee in Debre Markos University. And then a supportive letter was obtained from the zonal, District health administrations and the respective kebele level. An informed verbal consent was received from each study subjects and anyone who was not willing to take part in the study has the full right to stop interviewing at any time. To ensure confidentiality of respondents, their names and other personal identifiers were not recorded on the questionnaire.

\section{Result}

\section{Result for quantitative data}

A total of 370 pregnant mothers were participated in the study, making a response rate of $95.9 \%$.

The age of pregnant mothers included in this study ranged between 18 and 44 years with mean age $(+S D)$ of $27.78( \pm 5.73)$. The majority of them were orthodox Christians 341(92.2\%), married 360(97.3), house wife in occupation 337(91.1\%), having educational level of read or write 219(59.2\%), currently living with their partner 355(98.5\%).

Regarding distance from home to the nearest health facility that provide HIV testing, about half (53.8\%) of the participants were traveled $2.5-5 \mathrm{~km}$ on foot and the rest $20.8 \%$ and $25.4 \%$ participants were accessing up to 2.5 kilometers and above 5 kilometers of on foot travel respectively.

Above half (58.1\%) of participant's were gravida 2-4 and about quarter $(24.9 \%)$ was the first time pregnancy and the rest $17 \%$ experience 5 times and more.

Above half (53\%) of participants were previously tested for HIV for different purpose such as for marriage (39.3\%), to know their status (54.6\%) and other reasons (6.1\%).

\section{Socio-cultural contexts towards HIV/AIDS}

About three quarter (75.4\%) of participants stated that their cultural practices does not prohibit from getting HIV test though $8.9 \%$ of them stating as HIV testing contradicts their religious practice. Half of them want discuss their result with husband/partner (51.5\%) and would tell their result for their partner (76.8\%) (Table 1).

The respective expected level of caring attitude from their partners and the community if the test result becomes positive was $53.8 \%$ and $15.1 \%$.

\section{Knowledge and attitude of pregnant mothers towards HIV/ AIDS}

About three quarter (76.5\%) of pregnant mothers have adequate knowledge on HIV/AIDS mode of transmission and preventive measures. Majority (81.6\%) of participants knew transmission of HIV/

\begin{tabular}{|c|c|c|c|}
\hline Variable & Variable category & Frequency & Percent \\
\hline \multirow{6}{*}{$\begin{array}{l}\text { With whom you want } \\
\text { discuss the HIV test } \\
\text { result }\end{array}$} & With husband/partner & 189 & 51.1 \\
\hline & With parents & 64 & 17.3 \\
\hline & With brother and sister & 21 & 5.6 \\
\hline & With friends and neighbor & 12 & 3.2 \\
\hline & With health professionals & 76 & 20.5 \\
\hline & With no one & 8 & 2.2 \\
\hline \multirow{2}{*}{$\begin{array}{l}\text { Telling positive result for } \\
\text { partner }\end{array}$} & Yes & 284 & 76.8 \\
\hline & No & 86 & 23.2 \\
\hline \multirow{5}{*}{$\begin{array}{l}\text { Reason for not telling } \\
\text { positive result }\end{array}$} & Fear of rejection & 5 & 5.8 \\
\hline & Fear of breaking relationship & 46 & 53.5 \\
\hline & Fear of physical violence & 13 & 15.1 \\
\hline & Fear of not to blamed & 16 & 18.6 \\
\hline & Other & 6 & 6.9 \\
\hline \multirow{2}{*}{$\begin{array}{l}\text { Culture prohibit from } \\
\text { getting the service }\end{array}$} & Yes & 91 & 24.6 \\
\hline & No & 279 & 75.4 \\
\hline \multirow{2}{*}{$\begin{array}{l}\text { Religion prohibit from } \\
\text { getting the service }\end{array}$} & Yes & 33 & 8.9 \\
\hline & No & 337 & 91.1 \\
\hline \multirow[t]{2}{*}{ Bringing partner for test } & Yes & 288 & 80 \\
\hline & No & 72 & 20 \\
\hline
\end{tabular}

Table 1: Study participants' sociocultural contexts about HIVIAIDS in North-West Ethiopia, 2014.

AIDS during pregnancy and about $68.6 \%$ of them have good knowledge about MTCT of HIV/AIDS. Nearly two third (65.1\%) pregnant mothers knew the availability medication that can reduce MTCT of HIV.

Closely two third (61.1\%) participants have positive attitude towards HIV testing and above three forth (77\%) of them had intention to use ARV prophylaxis if the test result becomes positive. The rest $23 \%$ do not want to take the prophylaxis due to different reasons such as not to be recognized as patient of HIV/AIDS by their families or partners or neighbors (42.3\%), fear of drug side effect (10.5\%),by considering anti-retroviral prophylaxis not effective (37.5\%).

\section{VHCT service utilization and its determinants}

About three quarter $(76.2 \%)$ participants were tested for HIV in the current pregnancy. Among not tested (23.8\%), the frequently cited reason of not up taking VHCT service was fear of stigma and discrimination (40.9\%). Of not tested participants, about $73.8 \%$ have an intension to test for the future but the rest $26.2 \%$ do not have an intension due to different reasons like not eligible for testing because of trusting themselves (21.7\%) and their partners (30.4\%). About two third (63.8\%) participants were believed as VHCT was important for all persons and the rest agree only for special groups such as commercial sex workers $(6.8 \%)$, unmarried men $(3.8 \%)$, for newly married couples (5.7\%) and pregnant mothers (20\%).

The predictors that enhance utilization of VHCT services were being in age group of 25-35 compared $>35$ years, beliefs of VHCT importance for pregnant mothers only than for all person, disclosure of result for brother and sister compared partner, ability of bringing partners for test, having intension for anti-retroviral treatment, and having adequate knowledge about MTCT. But 6-10 years of being together with partner $<6$ and believing of VHCT importance before marriage only compared for all person would reduce VHCT utilization (Table 2).

\section{Result of qualitative data}

Qualitative data were collected to triangulate the finding of quantitative study and to get new insights on VHCT service utilization. 
Citation: Gidey B, Bizuayehu HM, Teshome M (2015) Voluntary HIV Counseling and Testing Service Utilization among Pregnant Mothers in North West Ethiopia In 2014. J AIDS Clin Res 6: 437. doi:10.4172/2155-6113.1000437

Page 4 of 6

\begin{tabular}{|c|c|c|c|c|c|}
\hline \multirow{2}{*}{ Variables } & & \multicolumn{2}{|c|}{ Used VHCT service } & \multirow{2}{*}{$\operatorname{COR}(95 \% \mathrm{Cl})$} & \multirow{2}{*}{ AOR $(95 \% \mathrm{Cl})$} \\
\hline & & Yes (\%) & No $(\%)$ & & \\
\hline \multirow{3}{*}{ Age } & $15-24$ & $95(76.6)$ & $29(23.4)$ & $4.125(2.144-7.936)$ & $1.785(0.454-7.012)$ \\
\hline & $25-35$ & $160(86.5)$ & $25(13.5)$ & $8.059(4.174-15.561)$ & $5.219(1.780-15.304)^{*}$ \\
\hline & $>35$ & $27(44.3)$ & $34(55.7)$ & 1 & 1 \\
\hline \multirow{3}{*}{ Years of being together } & $<6$ years & $116(85.3)$ & $20(14.2)$ & 1 & 1 \\
\hline & $6-10$ years & $85(72)$ & $32(627.4)$ & $0.458(0.245-0.855)$ & $0.341(0.128-0.913)^{*}$ \\
\hline & $>10$ years & $71(69.6)$ & $31(30.4)$ & $0.395(0.209-0.745)$ & $0.599(0.164-2.191)$ \\
\hline \multirow{4}{*}{ Educational status } & Unable to read and write & $161(73.5)$ & $58(26.5)$ & 1 & 1 \\
\hline & Only able to read and write & $42(72.4)$ & $16(27.6)$ & $0.940(0.491-1.799)$ & $1.921(0.643-5.733)$ \\
\hline & Attend elementary school & $48(87.3)$ & $7(12.3)$ & $2.455(1.052-5.731)$ & $1.876(0.573-6.145)$ \\
\hline & Attend high school and above & $31(81.6)$ & $7(18.4)$ & $1.534(0.639-3.683))$ & $0.622(0.181-2.138)$ \\
\hline \multirow{3}{*}{ Number of pregnancy } & First pregnancy & $77(83.7)$ & $15(16.3)$ & $3.159(1.490-6.697)$ & $1.156(0.236-5.674)$ \\
\hline & $2-4$ & $166(77.2)$ & $49(22.8)$ & $1.144(1.144-3.799)$ & $1.326(0.405-4.337)$ \\
\hline & $>5$ & $27(52.9)$ & $24(47.1)$ & 1 & 1 \\
\hline \multirow{5}{*}{ Importance of VHCT } & For Commercial sex worker & $11(44)$ & $14(56)$ & $0.195(0.083-0.458)$ & $0.329(0.081-0.1 .338)$ \\
\hline & For Unmarried men & $5(35.7)$ & $9(64.3)$ & $0.138(0.044-0.432)$ & $0.503(0.079-3.187)$ \\
\hline & Before marriage & $9(42.9)$ & $12(57.1)$ & $0.187(0.074-0.469)$ & $0.073(0.017-0.314)^{*}$ \\
\hline & For pregnant mothers & $68(91.9)$ & $6(8.1)$ & $2.818(1.153-6.889)$ & $6.370(1.690-24.012)^{*}$ \\
\hline & For all person & $189(80.1)$ & $47(19.9)$ & 1 & 1 \\
\hline \multirow[t]{2}{*}{ Prior testing } & Yes & $124((71.3)$ & $50(28.7)$ & $1.677(1.034-2.717)$ & $1.549(0.684-3.505)$ \\
\hline & No & $158(80.6)$ & $38(19.4)$ & 1 & 1 \\
\hline \multirow{2}{*}{ Bringing partners for test } & Yes & $247(85.8)$ & $41(14.2)$ & $8.434(4.754-14.96)$ & $4.427(1.640-11.953)^{*}$ \\
\hline & No & $30(41.7)$ & $42(58.3)$ & 1 & 1 \\
\hline \multirow{5}{*}{ Result disclosure } & For partner & 149(79.3) & $39(20.7)$ & 1 & 1 \\
\hline & For parents & $50(75.8)$ & $16(24.2)$ & $0.818(0.421-1.589)$ & $1.301(0.467-3.628)$ \\
\hline & For brother and sister & $16(76.2)$ & $5(23.8)$ & $0.838(0.289-2.428)$ & $9.005(1.318-61.524)^{*}$ \\
\hline & For health professionals & $53(71.6)$ & $21(23.4)$ & $0.661(0.357-1.223)$ & $1.711(0.618-4.735)$ \\
\hline & Other & $14(66.7)$ & $7(33.3)$ & $0.523(0.198-1.386)$ & $1.500(0.381-5.902)$ \\
\hline \multirow[t]{2}{*}{ ARV intension } & Yes & $243(85.3)$ & $42(14.7)$ & $6.824(3.985-11.685)$ & $4.207(1.368-12.940)^{*}$ \\
\hline & No & $39(45.9)$ & $46(54.1)$ & 1 & 1 \\
\hline \multirow[t]{2}{*}{ Culture } & Prohibit from testing & $42(46.2)$ & $49(53.8)$ & $0.636(0.347-1.163)$ & $1.159(0.421-3.193)$ \\
\hline & Not prohibit & $240(86)$ & $39(14)$ & 1 & 1 \\
\hline \multirow{2}{*}{ MTCT knowledge } & Adequate knowledge & $228(89.8)$ & $26(10.2)$ & $10.068(5.834-17.375)$ & $10.592(4.262-26.322)^{*}$ \\
\hline & Inadequate knowledge & $54(46.6)$ & $62(53.4)$ & 1 & 1 \\
\hline \multirow{2}{*}{ Existence of intervention } & Yes & $200(83)$ & $41(17)$ & $2.796(1.710-4.570)$ & $0.473(0.186-1.201)$ \\
\hline & No & $82(63.6)$ & $47(36.4)$ & 1 & 1 \\
\hline \multirow{2}{*}{ Attitude } & Positive attitude & $200(88.5)$ & $26(11.5)$ & $5.717(3.383-9.662)$ & $0.696(0.239-2.024)$ \\
\hline & Negative attitude & $82(56.9)$ & $62(43.1)$ & 1 & \\
\hline
\end{tabular}

*Significantly associated variable

$\mathrm{Cl}$ : Confidence interval; COR: Crude odds ratio; AOR: Adjusted odds ratio; ARV: Anti-retro viral

Table 2: The association of characteristics with VHCT service utilization among study participants in North-West Ethiopia, 2014.

Majority of FGD participants were having good knowledge about HIV/AIDS. All participants have positive attitude towards HIV testing. Most of the participants were mentioned as HIV testing during pregnancy was important for getting healthy baby. One urban participant said "I think HIV testing during pregnancy is important because it will help us to get a healthy baby"

\section{Knowledge about mother to child transmission of HIV/AIDS}

Some participants list the known modes of MTCT of HIV/AIDS. From the three mode of MTCT, majority have awareness of through breast feeding transmission. One rural participant explains MTCT during pregnancy as "... since the fetus is formed from the mother's blood that is infected by the virus, so the fetus is getting infected during period of conception."

\section{Factors affecting VHCT service utilization during pregnancy}

Fear of test result that means if the test result becomes positive the community will show stigma and discrimination especially in rural areas was mentioned as the main obstacle by all participants for not underwent testing. One participant stated as "if I got tested, my test result will be heard by different mechanisms and if my result becomes positive the communities will outcast me from different social ceremonies".

Majority of mothers participants' were fear the consequence of positive test result that is fear of divorce, loss of their properties and scattering of their families. One rural discussant stated "...If I am tested and the test result becomes positive it is difficult for me to live with the community so it is better not to test and living without difficulty."

Some participants were raised as having awareness problems like not knowing the availability of the service that avoid transmission of the virus from mother to the fetus.

Majority of the rural participants were not comfortable with HIV testing procedure. 
Some participants did not believe the effectiveness of prophylaxis which is given to prevent transmission of virus from HIV positive mother to fetus. Participants were also mentioned as some husbands are not interested on their wife HIV testing since the test result of his wife is enough to know his status.

\section{Discussion}

In this study about three quarter (76.2\%) pregnant mothers underwent HIV testing on current pregnancy and this finding was in in line with a study in Ghana (76\%) [14], Cambodia (76\%) [15] and it was lower than the studies conducted in Northwestern Ethiopia at Gondar town (82.5\%) [10], in a capital city of Ethiopia, Addis Ababa town (94\%) [12], in South Ethiopia at Hawassa Referral Hospital (96\%) [16], Southern Ethiopia (100\%) [17] and Northern Tanzania (98\%) [18]. The possible reasons for increment in prior studies might be using of health institution based study $[10,12,16-18]$ since pregnant mothers having positive attitude and better awareness may visit health institution and tested for HIV and in studies $[10,12,16,17]$ the study participants were living in town thus they can easily access the information about VHCT and health services for test. The current finding of VHCT uptake was also having slight increment when compared with a studies in Northwest Ethiopia (72.0\%) [9], Kumasi in Ghana (73.0\%) [19], Komfo Anokye Teaching Hospital in Ghana (73.9\%) [20], hospital ANC clients in western Kenya (68\%) [21], Uyam District in Nigeria (55.7\%) [22], Botswana (54\%) [23], and Oman (51.9\%) [24]. The reasons for discrepancy might be difference in integration of VHCT service with antenatal care (integrated in our context), time difference since trough time awareness creation might be done through mass media and sociocultural or health policy differences.

The frequently mentioned reason for not up taking VHCT service in this study was fear of stigma and discrimination both in qualitative and quantitative (40.9\%) results. This finding was supported by studies in Northwest Ethiopia [9,11] and other studies [9,12, 22, 16, 17, 25-28]. The reason of no tested for HIV in about $63.5 \%$ pregnant mothers in North-West Ethiopia was fear of rejection by the community if result become positive [9]. In Uyam District of Nigeria, the most common barrier to uptake of VHCT services in the community was fear of stigmatization (65.1\%) [22].

Participants in age group of 25-35 compared $>35$ years were more likely using VHCT service and this might be due to this participants would had many years of being together with couples since couples living more times were less likely using the service in current study because of trusting of each other.

The current finding revealed that about $68.6 \%$ of participants had good knowledge about MTCT of HIV/AIDS. This result was slightly higher than a study in eastern Uganda (60\%) [29] and lower than studies conducted in Addis Ababa, a capital city of Ethiopia i.e. (94\%) [12] and 90.3\% [30], Southern Ethiopia (92\%) [17], Oman (86.6\%) [24], Uyam District in Nigeria (71.6\%) [22]. The discrepancy of figures among prior studies each other and with current study might be due to differences in study population, study area, time of study conducted and other socio-economic differences.

In current study having adequate knowledge about MTCT would enhance utilization of VHCT by about 10.6 times and this finding was in agreement with prior studies [11,15,24,25,31]. A study in East Ethiopia at Dire Dawa showed as mothers having good knowledge on VHCT were 15.6 times more likely to be tested (AOR 95\% CI: $15.6(13,66.2)$ [25]. In Cambodia, pregnant mothers not knowledgeable about PMTCT of HIV/AIDS were $38 \%$ times less likely to take HIV test $(\mathrm{OR}=0.38$,
$\mathrm{CI}=0.22-0.66)$ [15]. The reason for this might be knowledgeable participants would have more intension use the service.

The current study revealed as having intension for ARV prophylaxis increases up take of VHCT by about 4.2 times and this finding is supported by a study in Gambella, Ethiopia [31].

Different evidences showed as male involvement is the crucial for VHCT acceptance $[18,28,32,33]$ and the current finding showed as participants having the ability of bringing partners for test would accept VHCT by about 4.4 times.

In current study the reason of using qualitative research method was to supplement the quantitative result and to get new opinions/ suggestions about VHCT using qualitative data.

In this study using probability participant selection method and using a community based approach would be considered as strengths since it enhance generalizability of the result. However, temporal association of factors cannot be assured due to using cross-sectional study design, using health professionals as data collectors would introduce social desirability bias, some questions like age, years since married were asking previous memory and this would introduce recall bias.

\section{Conclusion}

Majority (81.6\%) participants know transmission of HIV during pregnancy thought only about three quarter (76.2\%) tested for HVI in the current pregnancy. The repeatedly cited reason for not up taking VHCT service was fear of stigma and discrimination if test result become positive and others were lack of awareness, not believing the effectiveness of prophylaxis.

The predictors that enhance utilization of VHCT were being in age group of 25-35 compared $>35$ years, believes on VHCT importance for pregnant mothers only than for all person, disclosure of result for brother and sister compared partner, ability of bringing partners for test, having intension for ARV Prophylaxisis, and having adequate knowledge about MTCT. But 6-10 years of being together with partner than $<6$ years and believing of VHCT importance before marriage only compared for all person would reduce VHCT utilization.

\section{Recommendation}

\section{For national, regional, zonal and woreda health office}

- Improve acceptance of VHCT using different measures like by further enhancing health education on awareness creation, stigma and discrimination, blood drawing, effectiveness of prophylaxis.

- Involving other sectors to address socio-cultural barriers of HIV testing.

- Working with patient living HIV/AIDS associations to address stigma and discrimination and other barriers at the community and household level.

\section{For Health institutions and other interested organizations working on HIV/AIDS}

- Organizations working on VHCT should give especial attention for pregnant mothers not knowledgeable about MTCT of HIV/ AIDS; have not intension for ARV Prophylaxisis, unable to bringing their partner for test and those believing as VHCT was importance before marriage only. 
Citation: Gidey B, Bizuayehu HM, Teshome M (2015) Voluntary HIV Counseling and Testing Service Utilization among Pregnant Mothers in North West Ethiopia In 2014. J AIDS Clin Res 6: 437. doi:10.4172/2155-6113.1000437

- We recommend further research on issues of stigma and discrimination towards HIV/AIDS.

\section{Acknowledgement}

We would like to thank Debre Markos University and GAMBY College of medicine for giving the chance. Our deepest thank also goes to study participants and data collectors for their patience and commitment during data collection process.

\section{References}

1. WHO (2010) Guidelines on HIV and Infant feeding. 20 Avenue Appia, Geneva Switzerland.

2. WHO (2010 revision) Antiretroviral therapy of HIV infection in infants and children: towards universal access: recommendations for a public health approach.

3. Joint United Nations Program on HIVIAIDS (UNAIDS) (2011) world AIDS day report, Geneva, Switzerland.

4. Federal HIVIAIDS Prevention and Control Office Federal (2011) Guidelines for Prevention of Mother-to-Child Transmission of HIV In Ethiopia.

5. Central Statistical Agency (CSA) (2011) Ethiopia Demographic and Health Survey; final draft report. Addis Ababa Ethiopia, ICF International Calverton, Maryland, USA.

6. Ministry of Finance and Economic Development, Ethiopia (2010) MDGs Report Trends and prospects for meeting MDG by 2015. Addis Ababa, Ethiopia.

7. Williams DW, Eugenin EA, Calderon TM, Berman JW (2012) Monocyte maturation, HIV susceptibility, and transmigration across the blood brain barrier are critical in HIV neuropathogenesis. J Leukoc Biol 91: 401-415.

8. Newell ML, Coovadia H, Cortina-Borja M, Rollins N, Gaillard P, et al. (2004) Mortality of infected and uninfected infants born to HIV-infected mothers in Africa: a pooled analysis. Lancet 364: 1236-1243.

9. Belachew A, G/Maria A (2012) Factors Affecting Acceptance of HIV Counseling \& Testing Among Antenatal Care Attendants: With Emphasis on Role of Male Partners. International Journal of Scientific and Engineering Research 3: 1-11.

10. Malaju MT, Alene GD (2012) Assessment of utilization of provider-initiated HIV testing and counseling as an intervention for prevention of mother to child transmission of HIV and associated factors among pregnant mothers in Gondar town, North West Ethiopia. BMC Public Health 12: 226.

11. Moges Z, Amberbir A (2011) Factors associated with readiness to VHCT service utilization among pregnant mothers attending antenatal clinics in northwestern Ethiopia: a health belief model approach. Ethiop J Health Sci: 21.

12. Deressa W, Seme A, Asefa A, Teshome G, Enqusellassie F (2014) Utilization of PMTCT services and associated factors among pregnant mothers attending antenatal clinics in Addis Ababa, Ethiopia. BMC Pregnancy and Childbirth 14 328.

13. AVERT organization (2007) AIDS and HIV information from AIDS around the world.

14. Asefa A, Beyene H (2013) Awareness and knowledge on timing of mother-tochild transmission of HIV among antenatal care attending mothers in Southern Ethiopia: a cross sectional study. Reproductive Health 10: 66

15. Sasaki Y, Ali M, Sathiarany V, Kanal K, Kakimoto K (2010) Prevalence and barriers to HIV testing among mothers at a tertiary care hospital in Phnom Penh, Cambodia. Barriers to HIV testing in Phnom Penh, Cambodia. BMC Public Health 10: 494.

16. Abajobir AA, Zeleke AB (2013) Knowledge, Attitude, Practice and Factors Associated with Prevention of Mother-to-Child Transmission of HIVIAIDS among Pregnant Mothers Attending Antenatal Clinic in Hawassa Referral Hospital, South Ethiopia. J AIDS Clin Res 4: 215.

17. Merdekios B, Adedimeji AA (2011) Effectiveness of interventions to prevent mother-to-child transmission of HIV in Southern Ethiopia. Int J Womens Health 3: 359-366.

18. Falnes EF, Tylleskär T, Manuela PM, Manongi R, Engebretsen IMS (2010) Mothers' knowledge and utilization of prevention of mother to child transmission services in northern Tanzania. J Int AIDS Soc 13: 36.

19. Holmes C, Preko P, Bolds R, Baidoo J, Jolly P (2008) Acceptance of Voluntary Counseling Testing and Treatment for HIV Among pregnant mothers in Kumasi, Ghana. Ghana Med J 42: 8-15.
20. Addo V (2005) Pregnant Mothers's Knowledge of and Attitudes to HIV Testing at KATH. Ghana Med J 39: 50-54.

21. Hoog AHV, Mbori-Ngacha DA, Marum LH, Otieno JA, Misore AO, et al. (2005) Preventing mother-to-child transmission of HIV in western Kenya. J Acquir Immune Defic Syndr 40: 344-349.

22. Hembah-Hilekaan SK, Swende TZ, Bito TT (2012) Knowledge, Attitudes and Barriers towards Prevention of Mother-To-Child Transmission of HIV among Mothers Attending Antenatal clinics in Uyam District of Zaki-Biam in Benue State, Nigeria. Afr J Reprod Health 16: 27-34.

23. Thior I, Gabaitiri L, Grimes J, Shapiro R, Lockman S, et al. (2007) Voluntary counseling and testing among post-partum women in Botswana. Patient Educ Couns 65: 296-302.

24. Al-Jabri AA, Youssef RM, Hasson SS, Balkhair AA, Al-Belushi M, et al. (2014) Knowledge, attitudes and intended behaviours towards HIV testing and selfprotection: a survey of Omani pregnant mothers. EMHJ 20: 614-622.

25. Demissie A, Deribew A, Abera M (2009) Determinants of acceptance of voluntary HIV testing among antenatal clinic attendees at Dil Chora Hospital Dire Dawa, East Ethiopia. Ethiop J Health Dev 23: 141-147.

26. Reginald NKG, Bright SA, Kwame OB, Edmund B, Valerie CA (2014) Educational status and religion influence uptake of voluntary HIV counseling and testing by Ghanaian antenatal clinic attendees. Advances in Life Science and Technology 17.

27. Wangwe PJT, Nyasinde M, Charles DSK (2013) Counselling at primary health facilities and level of knowledge of antenatal attendees and their attitude on prevention of Mother to Child Transmission of HIV in Dar-es salaam, Tanzania. Afr Health Sci 13: 914-919.

28. Morfaw F, Mbuagbaw L, Thabane L, Rodrigues C, Wunderlich AP, et al. (2013) Male involvement in prevention programs of mother to child transmission of HIV: a systematic review to identify barriers and facilitators. Systematic Reviews 2: 5.

29. Byamugisha R, Tumwine JK, Ndeezi G, Karamagi CAS, Tylleskär T (2010) Attitudes to routine HIV counseling and testing, and knowledge about prevention of mother to child transmission of HIV in eastern Uganda: a crosssectional survey among antenatal attendees. J Int AIDS Soc 13: 52

30. Jebessa S, Teka T (2005) Knowledge and attitude towards mother to child transmission of HIV and its prevention among post-natal mothers in Tikur Anbessa and Zewditu Memorial Hospitals, Addis Ababa. Ethiop J Health Dev 19: $211-218$.

31. Fanta W, Worku A (2012) Determinants for refusal of HIV testing among women attending for antenatal care in Gambella Region, Ethiopia. Reprod Health 9: 8

32. Haile F, Brhan Y (2014) Male partner involvements in PMTCT: a cross sectiona study, Mekelle, Northern Ethiopia. BMC Pregnancy Childbirth 14: 65.

33. Ditekemena J, Koole O, Engmann C, Matendo R, Tshefu A, et al. (2012) Determinants of male involvement in maternal and child health services in subSaharan Africa: a review. Reprod Health 9: 32 